\title{
Use Studies: A Selective Review
}

\section{Nancy J. Bułkovich}

\begin{abstract}
Librarians have conducted hundreds of studies exploring various aspects of collection use in libraries. Most studies are of journal collections in academic libraries; however, the principles of conducting use studies are generally applicable to other materials and other types of libraries. Use studies can be conducted in a wide variety of ways, and they can measure different aspects of the use of a collection. Each method has its own particular strengths and weaknesses. If a combination of methods is used, the weaknesses of each method can be offset by the strengths of the others, and a truer picture of overall use can then be obtained.
\end{abstract}

$\mathbf{L}$ studies exploring various aspects of collection use in libraries (Millson-Martula 1988). Most of the works reviewed in this article are about studies of journal collections in academic libraries; however, the principles of conducting use studies are generally applicable to other materials or types of libraries. In its broadest sense, use is defined as "whether and/or how often a book, periodical, or segment of the collection is used" (Christiansen, Davis, and Reed-Scott 1983, 434). In practice, however, there is no agreement on what a "use," (Broadus 1985a; Metz and Litchfield 1988; Rice 1979) let alone "low use," really is; the definitions vary according to local needs (Millson-Martula 1988).

A use study is any method of data retrieval that answers, or helps to answer, basic questions regarding the acquisition, storage, and retention of materials in the collection. There are many different types of use studies, and each has certain strengths and weaknesses. Nonetheless, librarians continue to conduct them in an effort to manage various aspects of their collections.
In this paper, I will take the broad view of what constitutes a use study. I will review a variety of different methods that have been discussed in the literature. These include core lists and opinion surveys, reshelving studies, patron observation, circulation studies, interlibrary loan and other form-based requests, citation analyses, and impact factors. The measurement of non-use of collections will also be examined. This paper will conclude with a mock use study that applies many of the different methods discussed in this paper.

Use studies are conducted for a variety of reasons. One of the most common given is to aid in deciding which serial subscriptions could be cut (for example, Alldredge 1983; Chrzastowski 1991; Evans 1990; Milne and Tiffany 1991b; Naylor 1990; Veenstra and Wright 1988). Other reasons include adding new titles (Evans 1990), determining a need for duplicate subscriptions (Naylor 1990; Veenstra and Wright 1988), transferring material to storage locations (Christiansen, Davis, and Reed-Scott 1983; Fjallbrant

Nancy J. Butkovich is physical sciences librarian, Penn State University, University Park (njb@psulias.psu.edu). The author thanks Linda Musser and Bonnie MacEwan, both of Penn State, for their comments and criticisms. Invited manuscript received and accepted for publication May 31, 1996. 
1984; Harris 1977; Rice 1979; Taylor 1976-1977; Veenstra and Wright 1988) or withdrawal of materials (Fjallbrant 1984; Harris 1977; Rice 1979), and justification of previous serial cancellations (Bustion and Treadwell 1990). Data may also be used to determine which titles are essential, and the distribution of collection development funds may be based on use data. In addition, use studies can identify who is using the collection as well as what is being used (Christiansen, Davis, and Reed-Scott 1983).

Just as there are different reasons for conducting a use study, there are also a variety of problems associated with them. Some of the more commonly mentioned ones include staffing requirements (MillsonMartula 1988), the expense of running the survey, and questions concerning methodology and validity (Broadus 1985a; MillsonMartula 1988). There is often concern that quantitative measures alone do not accurately reflect use. "Subjective factors, such as value or relevance to the curriculum ..." (Millson-Martula 1988, 128) are also important.

Patrons might not cooperate with use studies, and might actively try to bias the survey results (Milne and Tiffany 1991a; Naylor 1994). They can also unintentionally distort results. For example, in reshelving studies using the sweep method, the materials that users reshelve themselves are not included in the final count, resulting in an underreporting of actual use (Broadus 1985b; Naylor 1993; Naylor 1994).

Information use patterns vary among disciplines (Metz and Litchfield 1988; Naylor 1990), and information formats differ in the way they are used (Metz and Litchfield 1988). The number of people working locally within a discipline should also be considered (Naylor 1990). Singlefaceted use studies cannot measure total use. Instead, as was noted about reshelving studies, they measure some subset of total use (Rice 1979). Consequently, multiple approaches to use studies are better because they allow the librarian to get a more complete picture of the whole than would be possible if only one method were employed.
Authors often disagree, however, about the relative value of a particular method. For example, Broadus states that "If proper allowances are made, counts based on the JCR [Joumal Citation Reports] can be almost as good as expensive local studies for predicting use of periodicals in a given library" (1985a, 33). On the other hand, Line declares that "no measure of journal use other than one derived from a local use study is of any significant practical value to librarians" $(1978,315)$.

Use studies vary considerably in their duration. Some circulation studies last just a few days. In an effort to determine the shortest reasonable time length for a circulation study, Metz and Litchfield conducted a study that utilized sets of data gathered at two different times several years apart. In the first interval, they examined all the materials circulating on a particular day. They also examined circulation over a period of several months. After comparing the results, they concluded that three days was probably the shortest duration for a reasonably representative circulation study, provided that the sample size was sufficiently large (Metz and Litchfield 1988). A similar conclusion was reached by Bulick, Sabor, and Flynn (1979).

Some of the most common studies are reshelving studies of various types. A fairly common, though by no means universal, time length is one year (Alldredge 1983; Gossen and Irving 1995; Milne and Tiffany 1991a, 1991b; Naylor 1990; Schmidt, Davis, and Jahr 1994). However, a circulation study of monographs at the University of Pittsburgh lasted more than seven years (Bulick, Sabor, and Flynn 1979; Kent 1979). Longer time lengths have a major advantage over shorter ones, at least in academic institutions, because they even out variations in use caused by the academic calendar (Milne and Tiffany 1991b; Naylor 1990; Schmidt, Davis, and Jahr 1994).

Line and Sandison warn that "ranked lists of crude 'uses' are valueless" (1975, 393). They state that librarians should consider "how many uses per monetary unit each journal provides .... [and] ... 
the number of uses per unit of shelf space ..." (Line and Sandison 1975, 393; italics in original). Several authors have incorporated, or at least considered, one or both of these concepts in their work (for example, Gossen and Irving 1995; Rice 1979; Rooke 1990).

Veenstra and Wright noted "a significant inverse relationship between the size of a library periodical collection and the percentage of the journal collection that may be expected to receive use" (1988, 171). The same observation was also made by Flynn (1979). Intuitively, however, this seems logical, because smaller collections would probably have a heavily-used core collection and very few marginal titles. A larger collection, simply because it is larger, would probably have the same heavily used core, but also have a higher percentage of the titles that are outside the core.

\section{CoRe Lists and Opinion SURVEYS}

Although core lists do not measure use, they do give an indication of the importance of a given title to some individual or organization. Titles appearing on these lists can vary considerably from institution to institution. Line noted that "A glance at the list of the most requested journals [from the British Library Lending Division] shows that they are all high-status, high-use, commonly held journals" (1978, 313).

There are different types of core lists. For example, accrediting agencies might have a list of required or recommended titles that they expect to see in libraries supporting departments or institutions wishing to receive or to maintain accreditation (Millson-Martula 1988). The American Chemical Society (ACS) is a good example of this. The ACS has a list of recommended and required serials that it deems necessary to support an undergraduate chemistry curriculum (American Chemical Society 1993).

Within an academic institution there are also core lists that have been prepared internally and consist of lists of titles considered to be essential for teaching or research. These are generally produced by polling faculty (Bustion and Treadwell 1990; Schmidt, Davis, and Jahr 1994). In one study the core lists were prepared using opinion surveys prepared by the faculty, who were asked to list the titles they felt were most important. When the results were compared with data obtained from other studies based on citation and circulation data, the investigators found that virtually the entire core list appeared in one or the other of the two studies (Schmidt, Davis, and Jahr 1994). Sometimes core list polls are included in questionnaires that cover "all aspects of periodical use of the library" (Ambia 1991).

In other cases faculty were presented with a list of titles and asked to assign a value measure to them (Bustion and Treadwell 1990; Fjallbrant 1984; Naylor 1990). These studies generally confirmed that low-ranked titles on faculty surveys were seldom used in reshelving studies (Bustion and Treadwell 1990; Fjallbrant 1984). The authors of one study also found that there was very little correlation between the faculty-generated lists of essential titles and the reshelving data (Bustion and Treadwell 1990).

Some opinion studies are based on the professional judgment of librarians rather than the academic faculty. In one study librarians considered "language of publication, to see whether it was a language taught on campus; whether the journal was indexed and if the indexes were held in the library; and the appropriateness of the title to the curriculum" (Swigger and Wilkes 1991, 43). In another study in which some academic departments chose not to rank titles, librarians developed cancellation lists based on "their best judgment" (Bustion and Treadwell, 1990, 43). In a study described by Broadus, White concluded "that the subjective judgments made by librarians have in general been correct in regard to what subscriptions should be discontinued" (Broadus 1985b, 58).

Opinion studies produce results that might be of questionable value because the motives of the people producing the lists are unknown. Also, various groups prepare lists in different ways. Therefore, the level of participation by individuals 
within a group is uneven (Swigger and Wilkes 1991). Care should be taken that the number of people surveyed is large enough to produce valid results. The same statement also applies to the number of people who respond to a survey (Veenstra and Wright 1988). Patrons might also incorrectly remember which journals they use (Broadus 1985b). Use by researchers and students in other areas should be considered, because users outside a given discipline could have different needs than users within (Greene 1993). Nonetheless, opinion studies, particularly those based on faculty responses, are often an important, and in some cases, the only basis used by librarians to make collection development decisions (Millson-Martula 1988).

\section{Reshelving Studies}

Reshelving studies are popular for gathering use data, and the use of both bound and unbound journals have been analyzed using them (Chrzastowski 1991; Milne and Tiffany 1991b; Naylor 1990, 1993, 1994).

There are two broad types: sweep studies and check-off studies. The sweep method measures what patrons take off the shelf and leave for library staff to count and reshelve (Ambia 1991; Evans 1990; Konopasek and O'Brien 1984; Naylor $1990,1993,1994)$. The check-off method requires patrons to tick off each use of a volume or issue on some sort of tally sheet or sticker attached to the covers of the items being surveyed (Konopasek and O'Brien 1984; Milne and Tiffany 1991a; Naylor 1993, 1994).

In some cases items were found that had been misshelved or otherwise disturbed. These were often included in reshelving results (Alldredge 1983; Evans 1990; Konopasek and O'Brien 1984; Naylor 1993), as were titles that had been used for interlibrary loan (Evans 1990; Fjallbrant 1984).

Both methods have their weaknesses. The sweep method requires an investment of staff time to record the data. It does not record use where patrons reshelve the materials themselves (Naylor 1993, 1994). Depending on the local cir- cumstances this can be a significant portion of the total use. Two reshelving studies using the sweep method yielded results representing only $20 \%-25 \%$ and $40 \%$ respectively of the total use (Taylor 1976-1977), while a third reported an average of 19 uses in which material was reshelved by patrons for every item left for library staff to reshelve. This undercounting varied by discipline (Harris 1977). Still another noted that "In all cases of use for less than ten minutes, the journal was reshelved [by the patron]" (Wenger and Childress 1977, 294). Finally, this method does not take into account how patrons used the materials. "Whether that happened because someone looked at the table of contents, read one article, or read the whole issue remains unknown" (Swigger and Wilkes 1991, 42).

In theory the check-off method eliminates, at least in part, these weaknesses, in that it puts the onus of data recording on the patron instead of the library staff. In practice, however, users often did not record the use (Naylor 1993, 1994). Also, patrons sometimes appeared to inflate use by making multiple ticks for a single use (Naylor 1994).

In studies of the same collection using the two methods, the sweep method produced use levels at least $40 \%$ higher than those obtained by the check-off method (Naylor 1993; Naylor 1994). In another study, researchers checked reshelving data obtained using the check-off method and determined that the check-off method underreported actual use by one third (Milne and Tiffany 1991a, 1991b).

\section{Non-Use STUdies}

Although reshelving studies usually register use, they can also be used to measure non-use of a collection.

Non-use studies are relatively simple to conduct (Alldredge 1983; Rooke 1990), but they are susceptible to error. They do not attempt to determine why a title is seldom used. This method is either a yesit's-used or no-it's-not-used method; it cannot accurately register multiple uses or identify how volumes are used (Rooke 
1990). It can, however, indicate whether in-house materials were used and reshelved by patrons (Harris 1977).

One such study utilized a variation of the check-off method, with a sticker on the cover of a current issue being checked-off when it was reshelved (Alldredge 1983). Other studies addressed non-use of bound journals. This was often determined by markers inserted into volumes in such a way that anyone using a given volume would be forced to disturb the marker (Harris 1977; Rooke 1990; Taylor 1976-1977). Sauer studied both "nonuse of current [journal] issues and nonuse of bound volumes and microfilms" $(1990,100)$. Over half of the titles with unused current issues also had unused back runs.

To establish a control, higher use titles are sometimes used (Rooke 1990; Taylor 1976-1977). In both studies, researchers converted the raw data into an index number using equations that compensated for different variables (Rooke 1990) or the amount of shelf space needed to house the title being surveyed (Taylor 1976-1977). Rooke figured use data and the size of a title's backfile into calculations that eventually generated a cost-per-use figure. Although studies that approximate the density of use can be valuable, they can be misleading because some titles can be high use titles yet still have low densities of use. Attempting to store or cancel these titles can have serious implications for the patrons (Wenger and Childress 1977).

\section{Circulation}

Circulation studies are useful because they can measure use, such as undergraduate use, that might not be reflected in other study techniques. They also can measure what is actually being removed from the library and which patron groups borrow the materials. Because the data are easy to obtain and because factors influencing the data, such as time length and amount of material used, can be controlled, the data can be manipulated and analyzed in a variety of different ways (Christiansen, Davis, and Reed-Scott 1983).

Circulation studies fall into several broad categories. In one study, the author looked at what was actually checked out during a given time span (Chrzastowski 1991). In some cases circulation figures also included reshelving data (Schmidt, Davis, and Jahr 1994). Other authors examined the characteristics of everything that was in circulation at a given time (Metz and Litchfield 1988). Still another considered circulation history based on the dates that items circulated. Taylor considered any title that met the criteria set in his 15/5 Circulation Rule as a candidate for remote storage. He defined this rule as "all volumes of that title which were published in the last fifteen years [and that] have not been borrowed during the last five years" (1976-1977, 38).

In comparing circulation statistics with reshelving data, Metz and Litchfield (1988) found that circulation data reflected in-house use fairly accurately. Others took this analysis a step further and noted that circulation data also mirrored interlibrary loan lending (Bulick, Sabor, and Flynn 1979). Neither variations in time nor different methods of analysis appeared to cause any major fluctuation in the data (Metz and Litchfield 1988), and a correlation, which varied by subject, seemed to exist between external circulation and internal reshelving data (Harris 1977).

Researchers at the University of Pittsburgh were able to establish circulation histories for monographs added to the collection in the first year of the study (Bulick, Sabor, and Flynn 1979). Reshelving data was also used to check the circulation data. They found enough correlation to "conclude that in terms of whether or not a book or monograph is ever used, it is sufficient to examine the external patron circulation data" (29).

Schad (1979), however, raised several objections to the Pittsburgh study. In critiques relevant to circulation studies, Schad argued that not all circulation transactions are recorded in an electronic system, and that books may be used without being checked out. Christiansen, Davis, and Reed-Scott (1983), made these same observations in comments regarding circulation studies in general. 
Generalizing Schad's objections, circulation studies measure past use; future use might be quite different as research areas change, and circulation based on instructional use will be radically different from circulation based on research use (Schad 1979; Voigt 1979). In cases where date due stamps are counted, undercounting can occur when items are checked out or reshelved but are not stamped (Harris 1977).

\section{Pathon Observations}

Not everyone takes library materials to a table or out of the library to use them. Many people, for various reasons, choose to use the items in the stacks, and they often reshelve the materials themselves. In either case the materials that they use, whether monographs or serials, do not get included in use studies based on reshelving statistics.

One method for obtaining information about materials reshelved by patrons is the unobtrusive study. In this method, patrons are observed and the number of items they use are counted, while the patron remains unaware of the observer (Bustion, Eltinge, and Harer 1992; Ross 1983).

Like all other methods of measuring use, however, this too has its weaknesses. The observers need training in what they are to look for and how to interpret what they see. Another potential problem is that the observer often will be unable to identify specific titles being used, a problem that does not affect other methods of determining use. Finally, cost is also a factor. The unobtrusive observation method is significantly more expensive to use than a reshelving study (Bustion, Eltinge, and Harer 1992). The results can be worth the effort, however. Ross noted that each patron observed during that study removed an average of 6.74 books and reshelved an average of 5.52 books (1983).

Flynn (1979) used an obtrusive method that involved searching the journal stacks for patrons using journals. The observer would then either interview patrons about their use or would request that the patrons complete a form concern- ing their use of the journals. Some problems were noted with this approach. In some cases users refused to answer some survey questions. In other cases the information patrons provided did not fit in the categories on the forms. Also, some patrons left before the observer could conduct the survey.

\section{Citation analysis and IMPACT FACTORS}

Citation analysis is a method that analyzes the characteristics of references cited in published literature. Although Broadus (1985a) states that citation analysis is quite useful and sufficiently accurate to replace local studies, several others remain unconvinced (Chrzastowski 1991; Naylor 1990; Rice 1979; Scales 1976; Swigger and Wilkes 1991). Swigger and Wilkes (1991) qualify their position by arguing that citation studies could be very useful if they were used in conjunction with other methods. They also observe that smaller libraries, because they are less likely to support large and varied research programs, would probably find the generic citation rankings to be more useful than large institutions.

Certainly citation studies based on an entire citation index have well-documented problems. Some of the most obvious are: only the first author of a cited work is listed; there is no authority control for author or journal names; some titles are so truncated as to be unusable; and citations by many patron groups are not included because their written output is not indexed (Schmidt, Davis, and Jahr 1994). Also, many citations are omitted because the literature of some disciplines is not well represented (Broadus 1985a; Swigger and Wilkes 1991) and because only journals are used to produce the Joumal Citations Report. Other formats, which also contain citations to bodies of work, are omitted (Scales 1976). There is also a possibility that "the citation rankings in JCR are of more use for American than for British libraries, but ... no firm conclusion of this sort can be drawn" (Scales 1976, 21). Citation patterns can vary within subject areas as well as across 
subject boundaries. Time lag in various stages of the publication cycle can also influence citation data (Christiansen, Davis, and Reed-Scott 1983).

On a more fundamental note, there are problems inherent in the citations themselves. For instance, authors commonly use some types of materials that rarely get cited (Schmidt, Davis, and Jahr 1994), and "It is possible that some authors cite articles they have never read . . . . [Also,] faculty research interests may change, so past citations of a journal may not predict future use" (Swigger and Wilkes 1991, 44).

Different user populations may use the same body of literature in different ways. For example, McCain and Bobick compared citations in faculty articles, student dissertations, and "qualifying briefs written by second-year students entering the Ph.D. program" (1981, 258). They found that, even though all three populations were related to each other, there were significant differences in the way each population used the same collection (McCain and Bobick 1981).

An additional problem is that the author may not have used a library copy, even though the title is present on the library shelves (Swigger and Wilkes 1991). Also, libraries may not own everything cited by their users (Schmidt, Davis, and Jahr 1994). Intuitively, one suspects that this would not be true with citation studies of undergraduate papers, particularly because undergraduates often do not have access to interlibrary loan facilities. In just such a study, Magrill and St. Clair (1995) made this assumption, because they saw no evidence to the contrary.

Nonetheless, citation studies can be quite useful if these limitations are kept in mind. In an academic setting, they can identify heavily used titles, provided that "undergraduate use is not ordinarily heavy, or if most users come from the primary constituency of the library" (Schmidt, Davis, and Jahr 1994, 63; underlining in original). Even when using online citation indexes, one can target that "primary constituency" by limiting the study to users within a specific location or zip code. Studies of online citation indexes have been an integral part of journal collection development in the Physical Sciences Library at Penn State for several years. SCISEARCH has also been successfully used for local citation data by working with the corporate source field and then analyzing the citations appearing in the articles retrieved (Green 1993).

Collection use by undergraduates is not reflected in citation studies based on the journal literature, yet undergraduates constitute the largest patron population in academic libraries. In an effort to understand use patterns of this critically important patron category, Magrill and St. Clair (1995) did a citation analysis of undergraduate papers from four academic institutions-two universities having an emphasis in scientific and technical research, and two church-supported liberal arts colleges. They found that science students listed approximately two times the number of references in their papers as humanities or social sciences students. Also, nearly two-thirds of the references listed by science undergraduates were to journal articles, while humanities undergraduates used approximately the same percentage of books. Social sciences students used journals at a slightly higher rate than humanities students.

Another value generated by the citation data is the impact factor of a journal. The impact factor "measures the number of times the articles in a journal have been cited in a given time period, divided by the number of articles in that journal" (Schmidt, Davis, and Jahr 1994, 47). Because it is based on a large body of literature cited by authors from many different countries, the impact factor assigned to a particular publication reflects international rather than local impact. One comparison of impact factors with local use data found that the correlation between them was weak (Schmidt, Davis, and Jahr 1994).

\section{INTERLIBRARY LOAN AND OTHER FORM-BASED METHODS}

Several authors, such as Evans (1990), have examined interlibrary loan statistics. These data can provide valuable information regarding the use of material that is 
not owned locally (Ambia 1991; Chrzastowski 1991) as well as identify which local holdings are lent to others outside the institution (Chrzastowski 1991; Fjallbrant 1984). Gossen and Irving (1995) compared data from a use study of bound and unbound journals with data from an ARL/RLG interlibrary loan cost-effectiveness survey.

Interlibrary loan guidelines stipulate that an institution may receive only five copies of articles from the five most recent years of a journal within any one year period. Any requests above this amount are considered outside the fair use provisions and are subject to copyright royalty payments (Gossen and Irving 1995; Naylor 1990).

Because of copyright law requirements, interlibrary loan departments keep records of items requested from other institutions, particularly regarding journal articles. Therefore, these records are an excellent source of information regarding what is being borrowed from other institutions. It is best, however, not to rely on only one year's data, because the five copy limit is low enough that one patron could easily skew the results. However, if titles appear on the list year after year, then the title should become a candidate for addition to the collection.

The same logic holds true for external document delivery data, although many services allow patrons to order directly from them. Because, in these cases, the library is not being used as an intermediary, the library will have only a partial picture of the information being requested through this medium. Christiansen, Davis, and ReedScott discussed advantages and disadvantages of an internal document delivery study, which "simulates users walking into the library and each user looking for a particular item" (1983, 436).

Other form-based data sets are potential sources of use information. Photocopier use logs are one such method (Johnson and Trueswell 1978; Veenstra and Wright 1988). Others are requests for photocopies made by library staff (Ambia 1991) and requests for material housed at remote locations. The latter data source is currently being studied at Penn State.

\section{A Library Scenario}

The method or methods employed in any given library at any given time should depend on the needs of the library and the resources available for the study. As has been stated earlier, each different measure has its strengths and weaknesses, and they can gauge different aspects of collection use. Furthermore, although they can measure past or current use, they cannot measure future use, so use data should be collected on a regular basis.

Ideally, different methods should be used in tandem. Consider the scenario of a librarian in an academic setting who is responsible for a collection with extensive journal holdings. Because of the history of serials pricing during the past decade, this librarian might anticipate the possibility of having to conduct serials cancellation projects on an annual basis. What might the librarian do?

In this example, the librarian might choose to search the SCISEARCH database for local citation data. If journal holdings circulate and the local online catalog has the proper report generating capabilities, circulation data could be obtained. The librarian might also choose to poll the faculty using the collection as well as the library staff, particularly the staff who are close to the reshelving operations. Interlibrary loan data, both borrowing and lending, and other document delivery data could also be obtained. All of this information is usually available at a relatively modest cost, and can be collected in a reasonably short time frame.

Although the results are weighted in favor of faculty and graduate research interests instead of undergraduate and casual use, the inclusion of input from the library reshelving staff should moderate this bias somewhat. However, the librarian might also choose to superimpose on this annual process other use measures, which could be conducted on a less frequent basis.

For instance, a reshelving study using the sweep method might be conducted. Because this method does not consider who was using the collection but only what was being used, some of the imbalance 
between user populations could be eliminated. However, it still does not address the users who reshelve their own material. For this the librarian may decide to conduct a study of non-use of selected titles to verify the reshelving data. This might also be useful in the case of titles that are producing contradictory results in the different use studies. The librarian might also opt to study the people browsing the journal stacks. Although not as useful for particular titles, this method can provide a measure of the level of undercounting in other methods.

\section{ConCLUSIONS}

Use studies can be conducted in a wide variety of ways, and they can measure different aspects of the use of a collection. Each method has its own particular strengths and weaknesses. Unfortunately, results obtained from use studies are sometimes ignored, or if considered, weighted so lightly as to be unimportant (Millson-Martula 1988). However, many years of static or declining budgets combined with increasing prices for both serials and monographs require librarians to use every means possible to justify budgets. At the same time, costs of storing collections are also rising. Libraries can no longer afford to own everything, and low use materials, however they are defined, need to be identified.

This means that use studies become very important sources of justification data. If a combination of methods are used, their weaknesses can offset each other, and a truer picture of overall use might be obtained. A particular set of data can become obsolete, however, because the interests of the users are dynamic rather than static. Therefore, it is important to integrate use studies into the normal work flow of a library. By doing this, the data will be available when needed, and the librarian can confidently make appropriate collection decisions.

\section{Works CITED}

Alldredge, Noreen S. 1983. The non-use of periodicals: A study. Serials librarian 7, no. 4: $61-64$.

Ambia, Golam. 1991. Use of periodicals in physics in Delhi University Science Library, IIT Library, NPL Library: A comparative study. Libri 41: 98-108.

American Chemical Society, Committee on Professional Training. 1993. Journal list for undergraduate programs. Washington, DC: American Chemical Society.

Broadus, Robert N. 1985a. A proposed method for eliminating titles from periodical subscription lists. College \& research libraries 46:30-35.

$1985 \mathrm{~b}$. The measurement of periodicals use. Serials review 11, no. 2: 57-61.

Bulick, Stephen, William N. Sabor, and Roger Flynn. 1979. Circulation and in-house use of books. In Use of library materials-The University of Pittsburgh study. New York: Marcel Dekker.

Bustion, Marifran, John Eltinge, and John Harer. 1992. On the merits of direct observation of periodical usage: An empirical study. College \& research libraries 53: 537-50.

Bustion, Marifran, and Jane Treadwell. 1990. Reported relative value of journals versus use: A comparison. Collége of research libraries 51: 142-51.

Christiansen, Dorothy E., C. Roger Davis, and Jutta Reed-Scott. 1983. Guide to collection evaluation through use and user studies. Library resources \& technical services 27: $432-40$.

Chrzastowski, Tina E. 1991. Journal collection cost-effectiveness in an academic chemistry library: Results of a cost/use survey at the University of Illinois at Urbana-Champaign. Collection management 14 , nos. 1/2: 85-98.

Evans, Josephine King. 1990. Tracking periodical usage in a research library. College \& research libraries news 51: 958-9.

Fjallbrant, Nancy. 1984. Rationalization of periodical holdings: A case study at Chalmers University Library. Journal of academic librarianship 10: 77-86.

Flynn, Roger. 1979. Use of journals. In Use of library materials-The University of Pittsburgh study. New York: Marcel Dekker.

Gossen, Eleanor A., and Suzanne Irving. 1995. Ownership versus access and low-use periodical titles. Library resources \& technical services 39: 43-52.

Greene, Robert J. 1993. Computer analysis of local citation information in collection management. Collection management 17 , no. 4: 11-24. 
Harris, C. 1977. A comparison of issues and in-library use of books. ASLIB proceedings 29: 118-126.

Johnson, Carol A., and Richard W. Trueswell. 1978. The weighted criteria statistic score: An approach to journal selection. College \& research libraries 39: 287-92.

Kent, Allen. 1979. Background of the study. In Use of library materials-The University of Pittsburgh study. New York: Marcel Dekker.

Konopasek, Katherine, and Nancy Patricia O'Brien. 1984. Undergraduate periodicals usage: A model of measurement. Serials librarian 9, no. 2: 65-74.

Line, Maurice B. 1978. Rank lists based on citations and library uses as indicators of journal usage in individual libraries. Collection management 2: 313-16.

Line, Maurice B., and Alexander Sandison. 1975. Practical interpretation of citation and library use studies. College $\&$ research libraries 36: 393-96.

Magrill, Rose Mary, and Gloriana St. Clair. 1990. Undergraduate term paper citation patterns by disciplines and level of course. Collection management 12 , nos. $3 / 4$ : 2556.

McCain, Katherine W., and James E. Bobick. 1981. Patterns of journal use in a departmental library: A citation analysis. Journal of the American Society for Information Science 32: 257-67.

Metz, Paul, and Charles A. Litchfield. 1988. Measuring collections use at Virginia Tech. College \& research libraries 49: 501-13.

Millson-Martula, Christopher. 1988. Use studies and serials rationalization: A review. Serials librarian 15, nos. 1/2: 121-36.

Milne, Dorothy, and Bill Tiffany. 1991a. A cost-per-use method for evaluating the cost-effectiveness of serials: A detailed discussion of methodology. Serials review 17 , no. 2: 7-19.

1991b. A survey of the cost-effectiveness of serials: A cost-per-use method and its results. Serials librarian 19 , nos. $3 / 4$ : $137-49$.

Naylor, Maiken. 1990. Assessing current periodical use at a science and engineering library: A dBase III+ application. Serials review 16, no. 4: 7-19.

1993. A comparison of two methodologies for counting current periodical use. Serials review 19, no. 1: 27-34, 62 .

1994. Comparative results of two current periodical use studies. Library resources \& technical services 38: 373-88.

Rice, Barbara A. 1979. Science periodicals use study. Serials librarian 4, no. 1: 35-47.

Rooke, Su. 1990. Surveying non-usage of serials. Serials librarian 18, nos. 1/2: 81-96.

Ross, Johanna. 1983. Observations of browsing behavior in an academic library. College \& research libraries 44: 269-76.

Sauer, Jean S. 1990. Unused current issues: A predictor of unused bound volumes? Serials librarian 18, nos. 1/2: 97-107.

Scales, Pauline A. 1976. Citation analyses as indicators of the use of serials: A comparison of ranked title lists produced by citation counting and from use data. Journal of documentation 32: 17-25.

Schad, Jasper G. 1979. Missing the brass ring in the Iron City. Journal of academic librarianship 5: 60-63.

Schmidt, Diane, Elizabeth B. Davis, and Ruby Jahr. 1994. Biology journal use at an academic library: A comparison of use studies. Serials review 20, no. 2: 45-64.

St. Clair, Gloriana. 1995. Electronic mail message to author, 12 December.

Swigger, Keith, and Adeline Wilkes. 1991. The use of citation data to evaluate serials subscriptions in an academic library. Serials review 17 , no. 2 : $41-46,52$.

Taylor, Colin R. 1976-1977. A practical solution to weeding university library periodicals collections. Collection management 1 , nos. 3/4: 27-45.

Veenstra, Robert J., and James C. Wright. 1988. A review of local journal use studies: An investigation of possible broader applications. Collection management 10 , nos. 3/4: 163-73.

Voigt, Melon J. 1979. Circulation studies cannot reflect research use. Journal of academic librarianship 5: 66 .

Wenger, Charles B., and Judith Childress. 1977. Journal evaluation in a large research library. Journal of the American Society for Information Science 28: 293-99. 